\title{
Review Article \\ Integrins in Trabecular Meshwork and Optic Nerve Head: Possible Association with the Pathogenesis of Glaucoma
}

\author{
Yisheng Zhong, ${ }^{1}$ Jing Wang, ${ }^{1}$ and Xunda Luo ${ }^{2}$ \\ ${ }^{1}$ Department of Ophthalmology, Ruijin Hospital Affiliated Medical School, Shanghai Jiaotong University School of Medicine, \\ 197 Rui Jin Er Road, Shanghai 200025, China \\ ${ }^{2}$ Scheie Eye Institute, Department of Ophthalmology, University of Pennsylvania, Philadelphia, PA 19104, USA
}

Correspondence should be addressed to Yisheng Zhong; yszhong68@yahoo.com.cn and

Xunda Luo; luoxunda@mail.med.upenn.edu

Received 29 November 2012; Accepted 7 February 2013

Academic Editor: H. C. Van der Mei

Copyright ( 2013 Yisheng Zhong et al. This is an open access article distributed under the Creative Commons Attribution License, which permits unrestricted use, distribution, and reproduction in any medium, provided the original work is properly cited.

\begin{abstract}
Integrins are a family of membrane-spanning proteins that are important receptors for cell adhesion to extracellular matrix proteins. They also provide connections between the extracellular environment and intracellular cytoskeletons and are responsible for activation of many intracellular signaling pathways. In vitro and in vivo data strongly indicate that integrin-mediated signaling events can modulate the organization of the actin cytoskeleton in trabecular meshwork (TM) cells and are associated with astrocyte migration and microglia activation of the optic nerve head in patients with primary open angle glaucoma. Consequently, increase in resistance in the TM outflow pathways and remodeling of the optic nerve head occur, which in turn increases intraocular pressure (IOP), adds additional mechanical stress and strain to optic nerve axons, and accelerates damage of axons initially caused by optic nerve head remodeling. Integrins appear to be ideal candidates for translating physical stress and strain into cellular responses known to occur in glaucomatous optic neuropathy.
\end{abstract}

\section{Introduction}

Glaucoma is the second leading cause of blindness worldwide. It is estimated that there are 60.5 million people with glaucoma worldwide in 2010 and will increase to 79.6 million by 2020 [1]. Glaucoma is commonly defined as an optic neuropathy that is associated with characteristic structural damage to the optic nerve and associated with visual dysfunction that might be caused by various pathological processes [2-4]. Risk factors related to glaucoma include intraocular pressure (IOP), age, family history, clinical appearance of the optic nerve, race, and potential vascular disease [5-8]. IOP remains the most prominent risk factor of all, and lowering IOP is the mainstay of nearly all contemporary glaucoma therapies.

Several prospective randomized multicenter studies have identified that IOP reduction with either medication or surgery can lower the incidence of the disease and slow down progression of vision loss in glaucoma patients [9-15]. If IOP is beyond the tolerable range of the optic nerve, retinal ganglion cells (RGCs) axons degenerate at the optic nerve head in the region of the lamina cribrosa, a process that occurs in parallel to the apoptotic death of retinal ganglion cells (RGCs). The exact mechanisms that lead to the death of RGCs in glaucoma have not been fully identified but might include blockade of both anterograde and retrograde axonal transport which lead to deprivation of neurotrophic signals [4]. Glaucomatous neuropathy might occur in parallel to extracellular matrix (ECM) remodeling of the optic nerve head $[4,16,17]$.

IOP is generated in the anterior eye via the aqueous humor circulation system. The trabecular meshwork (TM) outflow pathway offers a certain resistance to aqueous humor outflow, and, in response to the resistance, IOP is generated $[18,19]$. In addition, there is an alternative uveoscleral pathway along the interstitial spaces of the ciliary muscle and the supraciliary space, of which physiological role is not fully understood [20]. Much evidence indicates that normal aqueous humor outflow resistance mainly resides in the inner wall region of the TM outflow pathways $[18,21]$. However, the 
exact structure and molecular nature of trabecular outflow resistance in the inner wall region are not clear. Two hypotheses have been proposed for the trabecular outflow resistance [22]. One hypothesis is based on the observation that banded fibrillar ECM in the juxtacanalicular region of the TM in glaucomatous eyes is significantly thicker than that seen in normal eyes $[23,24]$, which leads to the assumption that the elevation of outflow resistance is attributable to changes in the quantity and property of the ECM in this region $[25,26]$. The ECM hypothesis is supported by the observation that perfusion of anterior eye segments in organ cultures with metalloproteinases that digest ECM components leads to a reversible increase in outflow facility [27]. Another hypothesis is based on the discovery that the cells of TM have contractile properties [28] and that an increase in TM tone increases outflow resistance [29]. Thereby, an increase in the contraction state of TM cells in glaucoma might lead to higher rigidity of the TM and to an increased outflow resistance. The contractility hypothesis is supported by the observation that experimental disruption of the actin cytoskeleton of the TM decreases outflow resistance $[30,31]$ and by recent findings which provide evidence that the TM of patients with primary open angle glaucoma (POAG) is stiffer than that of age-matched controls [32]. The two hypotheses are not mutually exclusive, as it is possible that TM cells that increase their contractile capabilities simultaneously synthesize more fibrillar matrix to transmit more force.

Research efforts have been put in the last decade to elucidate cells response and ECM remodeling process in the TM and the optic nerve head in glaucoma, and integrins have been identified as very important participants in this process. The purpose of this paper is to summarize findings on integrins in pathogenesis of glaucoma.

\section{The Integrins and Their Ligands}

Integrins exist as heterodimers with $\alpha$ and $\beta$ subunits that interact noncovalently. At present, eighteen $\alpha$ - and eight $\beta$ subunits have been identified and known to form 24 different heterodimers (Table 1), and an addition of six $\alpha$-subunits and one $\beta$-subunit is now speculated, based upon analysis of the human genome [33-35]. Integrins are a family of membranespanning proteins that are important receptors for cell adhesion to ECM proteins. They also provide connections between the extracellular environment and intracellular cytoskeletons. In addition to their roles with ECM, they are now known to be responsible for activation of many intracellular signaling pathways to mediate many cell-cell interactions including those involved in inflammation, hemostasis, and cancer metastasis and to serve as cell receptors for viruses and bacteria [34].

Each integrin subunit appears to have one or more ligand to which it can bind. Specificity of ligand recognition for a heterodimer is influenced by the specific combination of subunits and relative affinity and availability of the ligands [36]. In general, integrin ligands can be classified into four categories: ECM, soluble molecules, cell-cell, and pathogens and toxins [33]. Ligands of integrins are listed in Table 1
TABLE 1: Human integrin subunits and their ligands.

\begin{tabular}{|c|c|c|}
\hline Integrin & Ligand & $\begin{array}{l}\text { Type of } \\
\text { receptors }\end{array}$ \\
\hline$\alpha 5 \beta 1$ & Fibronectin & \multirow{8}{*}{$\begin{array}{l}\text { RGD } \\
\text { receptors }\end{array}$} \\
\hline$\alpha 8 \beta 1$ & Fibronectin/vitronectin/nephronectin & \\
\hline$\alpha \mathrm{v} \beta 1$ & Fibronectin/vitronectin & \\
\hline$\alpha \mathrm{v} \beta 3$ & Vitronectin/fibronectin/fibrinogen & \\
\hline$\alpha \mathrm{v} \beta 5$ & Vitronectin & \\
\hline$\alpha \mathrm{v} \beta 6$ & Fibronectin & \\
\hline$\alpha \mathrm{v} \beta 8$ & Vitronectin & \\
\hline$\alpha \operatorname{IIb} \beta 3$ & Fibrinogen/fibronectin & \\
\hline$\alpha 1 \beta 1$ & Collagen I/collagen IV/collagen IX & \multirow{4}{*}{$\begin{array}{l}\text { Collagen } \\
\text { receptor }\end{array}$} \\
\hline$\alpha 2 \beta 1$ & Collagen I/collagen IV/collagen IX & \\
\hline$\alpha 10 \beta 1$ & $\begin{array}{l}\text { Collagen II/collagen IV/collagen } \\
\text { VI/collagen IX }\end{array}$ & \\
\hline$\alpha 11 \beta 1$ & Collagen I/collagen IV/collagen IX & \\
\hline$\alpha 3 \beta 1$ & Laminin-511/laminin-332/laminin-211 & \multirow{4}{*}{$\begin{array}{l}\text { Laminin } \\
\text { receptor }\end{array}$} \\
\hline$\alpha 6 \beta 1$ & $\begin{array}{l}\text { Laminin-511/laminin-332/laminin- } \\
\text { 111/laminin-411 }\end{array}$ & \\
\hline$\alpha 6 \beta 4$ & Laminin-511/laminin-332 & \\
\hline$\alpha 7 \beta 1$ & $\begin{array}{l}\text { Laminin-511/laminin-211/laminin- } \\
\text { 111/laminin-411 }\end{array}$ & \\
\hline$\alpha 4 \beta 1$ & Fibronectin/VCAM-1 & \multirow{7}{*}{$\begin{array}{l}\text { Leukocyte- } \\
\text { specific } \\
\text { receptors }\end{array}$} \\
\hline $\begin{array}{l}\alpha 4 \beta 7 \\
\alpha 9 \beta 1\end{array}$ & $\begin{array}{l}\text { MadCAM-1/fibronectin/VCAM-1 } \\
\text { tenascin-C/VEGF-C/VEGF-D }\end{array}$ & \\
\hline$\alpha \mathrm{D} \beta 2$ & ICAM-3/VCAM-1 & \\
\hline$\alpha \mathrm{L} \beta 2$ & ICAM-1/ICAM-2/ICAM-3/ICAM-5 & \\
\hline$\alpha \mathrm{M} \beta 2$ & $\mathrm{iC} 3 \mathrm{~b} /$ fibronectin + more & \\
\hline$\alpha \mathrm{X} \beta 2$ & $\mathrm{iC} 3 \mathrm{~b} /$ fibronectin + more & \\
\hline$\alpha \mathrm{E} \beta 7$ & E-cadherin & \\
\hline
\end{tabular}

RGD: arginine-glycine-aspartate, MadCAM: mucosal addressin cell adhesion molecule, ICAM: intercellular adhesion molecule, VCAM: vascular celladhesion molecule, and VEGF: vascular endothelial growth factor.

$[36,37]$. Integrins can be divided into four major types based on ligand sequences that they recognize, which are arginine-glycine-aspartate (RGD) receptors, collagen receptor, laminin receptor and leukocyte-specific receptors [37] (Table 1).

\section{Integrins in TM}

TM cell-matrix adhesion is crucial for the maintenance of the aqueous humor outflow resistance. ECM components in TM include fibronectin, laminin, vitronectin, types I, III, IV, V, and VI collagen, fibrillin-1, decorin, and others (Table 2) [3849]. Fibronectin, vitronectin, and collagen types I and IV are the major extracellular matrix proteins in human TM [50] and are ligands of integrins as well. Many biological activities of ECM in TM are mediated via integrin-ECM interactions [51]. It has been identified that steroid significantly increases fibronectin expression in TM cells $[52,53]$. Tissue/organ culture experiments suggest that overexpression of ECM components (laminin and collagen type IV, etc.) by TM cells 
TABLE 2: The extracellular matrix and integrins in trabecular meshwork and optic nerve head.

\begin{tabular}{|c|c|}
\hline Extracellular matrix & Integrin subunits \\
\hline \multicolumn{2}{|c|}{ Trabecular meshwork } \\
\hline Fibronectin & $\alpha 1$ \\
\hline Laminin & $\alpha 2$ \\
\hline Vitronectin & $\alpha 3$ \\
\hline Collagen type I & $\alpha 4$ \\
\hline Collagen type III & $\alpha 5$ \\
\hline Collagen type IV & $\alpha 6$ \\
\hline Collagen type V & $\alpha \mathrm{v}$ \\
\hline Collagen type VI & $\beta 1$ \\
\hline Collagen type XII & $\beta 3$ \\
\hline Fibrillin-1 & $\beta 4$ \\
\hline Decorin & $\beta 5$ \\
\hline Elastin & $\beta 6$ \\
\hline Cochlin & $\beta 7$ \\
\hline \multicolumn{2}{|l|}{ Thrombospondin-1 } \\
\hline \multicolumn{2}{|l|}{ VCAM-1 } \\
\hline \multicolumn{2}{|l|}{ Myocilin } \\
\hline \multicolumn{2}{|l|}{ Neuropilin-1 } \\
\hline \multicolumn{2}{|l|}{ Cadherin } \\
\hline \multicolumn{2}{|l|}{$\beta$-catenin } \\
\hline \multicolumn{2}{|l|}{ Sphingosine 1} \\
\hline \multicolumn{2}{|l|}{ Chondroitin sulfate } \\
\hline \multicolumn{2}{|l|}{ Heparan sulfate } \\
\hline \multicolumn{2}{|l|}{ Tenascin } \\
\hline \multicolumn{2}{|c|}{ Optic nerve head } \\
\hline Collagen type I & $\alpha \mathrm{l}$ (little expression) \\
\hline Collagen type III & $\alpha 2$ \\
\hline Collagen type IV & $\alpha 3$ \\
\hline Collagen type V & $\alpha 4$ \\
\hline Collagen type VI & $\alpha 5$ \\
\hline Collagens type VIII & $\alpha 6$ \\
\hline Collagens type IX & $\alpha \mathrm{v}$ \\
\hline Collagen type XVIII & $\beta 1$ \\
\hline Laminin & $\beta 2$ (little expression) \\
\hline Fibronectin & $\beta 3$ (little expression) \\
\hline Tenascin & $\beta 4$ \\
\hline \multicolumn{2}{|l|}{ Vitronectin } \\
\hline \multicolumn{2}{|l|}{ Elastin } \\
\hline \multicolumn{2}{|l|}{ Chondroitin sulfate } \\
\hline \multicolumn{2}{|l|}{ Dermatan sulfate } \\
\hline \multicolumn{2}{|l|}{ Aggrecan } \\
\hline \multicolumn{2}{|l|}{ Entactin/nidogen } \\
\hline \multicolumn{2}{|l|}{ Thrombospondin } \\
\hline \multicolumn{2}{|l|}{ Thrombomodulin } \\
\hline \multicolumn{2}{|l|}{ Endostatin } \\
\hline \multicolumn{2}{|l|}{ Cadherin } \\
\hline \multicolumn{2}{|l|}{ Periostin } \\
\hline Cartilage linking prote & \\
\hline
\end{tabular}

TABLE 2: Continued.

\begin{tabular}{ll}
\hline Extracellular matrix & Integrin subunits \\
\hline Fibulin 1 & \\
Decorin & \\
Perlecan & \\
Biglycan & \\
Versican & Fibromodulin \\
\hline
\end{tabular}

may play a role in the development of outflow resistance and contribute to the development of steroid-induced glaucoma and POAG $[24,54,55]$.

Integrins play a critical role in TM cell-matrix adhesion. In TM cell culture, attachment of cells to ECM proteins can be blocked by specific integrin antibodies, and cell adhesion to fibronectin and vitronectin can also be inhibited by peptides containing Arg-Gly-Asp (RGD) sequences [38]. Up to date, there are thirteen integrin subunits known to be expressed by TM cells (Table 2) $[38,39,43]$, and it is possible that more subunits might be found in the future. These integrins are distributed throughout the TM with the peak expression observed along cells on the beams, and the expression does not appear to vary with donor age [39]. In cultured human TM cell lines, expressions of $\alpha 2, \alpha 5$, and $\alpha \mathrm{v}$ integrin subunits changed consistently when dexamethasone is used, and there was no difference in expression patterns of any of these integrin subunits between cell lines obtained from normal and glaucomatous eyes [56]. In addition, connective tissue growth factor can also mediate upregulation of integrin subunits $\alpha \mathrm{v}$ and $\beta 1$ expressions in TM cells [57].

Integrins form important physical links between extracellular environment and intracellular actin cytoskeleton and may provide a mechanism to detect changes in external forces in the microenvironment of the TM [58]. Cross-linked actin networks (CLANs) are originally observed in spreading cells and are described as actin geodesic domes. CLANs are composed of interconnected arrays of three-to-five actin filaments extending outward from a central vertex. They may be precursors to actin stress fibers that regulate contractility in cells. Studies in cultured anterior segments and cultured TM cells treated with dexamethasone have suggested that steroid can lead to rearrangement of actin cytoskeleton into CLANs that resemble geodesic domes or polygonal actin networks [59-64]. CLANs have also been observed in cultured TM cells and in TM cells in isolated meshworks from glaucomatous donor eyes in the absence of any dexamethasone treatment $[65,66]$. CLANs have also been found in normal TM cells in isolated meshworks, albeit at a lower frequency than in glaucomatous TM [66, 67]. Recently, it has been suggested that CLANs formation in TM cells may reduce contractility of the tissue by increasing the rigidity of the cells and thus rendering them unable to change shape and "relax" under pressure. Alternatively, CLANs formation could impact other actin-mediated biological processes of the TM that are required for normal outflow facility such as attachment to the ECM, phagocytosis, and gene expression [68-70], which suggests that these actin structures could possibly be involved 
in pathogenesis of steroid-induced glaucoma and other forms of POAG $[62,63,68,70]$. CLANs formation can be regulated by $\beta 1$ and $\alpha \mathrm{v} \beta 3$ integrin signaling pathways. Distinct $\beta 1$ and $\alpha \mathrm{v} \beta 3$ integrin signaling pathways converge to enhance CLANs formation [42]. $\beta 1$-mediated CLAN formation is PI$3 \mathrm{~K}$ dependent, whereas $\beta 3$-mediated CLAN formation is CD47 and Racl/Trio-dependent and might be regulated by thrombospondin-1. Both integrin pathways are Src dependent $[58,71]$. Therefore, integrin-mediated signaling events can modulate the organization of the actin cytoskeleton in TM cells and consequently participate in regulation of cytoskeletal events previously demonstrated to be involved in regulation of outflow facility $[42,51]$.

It has been found that the active site in the heparin II (HepII) domain of fibronectin could regulate outflow facility in cultured anterior segment and disrupt actin cytoskeleton in transformed human TM (TM-1) cells, and the active site in the HepII domain is the syndecan/integrin binding sequence, PPRARI [72]. The PPRARI sequence in the HepII domain has been shown to serve as a physiological $\alpha 4 \beta 1$ ligand [73], and soluble anti- $\alpha 4$ integrin antibodies could inhibit Hep II domain-mediated cell spreading and soluble vascular cell adhesion molecule-1- ( $\alpha 4 \beta 1$-ligand) induced cell spreading, which suggests the Hep II domain mediates cell spreading and stress fiber formation through $\alpha 4 \beta 1$ integrin, a potentially key regulator of tissue contractility [74]. Recently, it has been reported that $\beta 1$ integrin functionblocking antibody inhibits adhesion and spread of TM cells on Galectin-8- (Gal8-) coated wells. Phosphorylated myosin light chain 2 (MLC2) accumulates in cells adhered to Gal8 and is associated with stress fiber formation that can be abolished by Rho inhibitor, C3 transferase, or Rho-kinase (ROCK) inhibitor Y27632. These findings suggest that $\beta 1$ integrins and the Rho/ROCK/MLC2 signaling pathway may be involved in Gal8-promoted cytoskeletal rearrangement in TM cells [75].

\section{Integrins in Schlemm's Canal}

It has been found that collagen I, IV, and laminin-511 are the prominent structural proteins in Schlemm's canal (SC) basement membrane [76], and SC cells express $\alpha 2, \alpha 3, \alpha 6$, $\beta 1$, and $\beta 4$ integrin subunits, and $\alpha 6$ is uniquely expressed by SC cells in situ in the conventional outflow tract and in vitro by cultured SC cells $[76,77]$. The integrin-mediated SC cell-matrix adhesion may have a critical role in maintaining a continuous barrier to fluid flow.

\section{Integrins in the Optic Nerve Head}

Known components of the ECM in the optic nerve head are listed in Table 2 [78-97]. It is possible that more new components of ECM in optic nerve head might be found in the future. The major ECM proteins of optic nerve head consist of collagen types I, III, V, and VI, along with elastin in the peripapillary sclera, cores of laminar beams, and retrobulbar optic nerve septae. The basement membrane components laminin and collagen type IV are identified along the margins of the laminar beams in association with astrocytes and within the beams in association with capillary vascular endothelium $[82,83]$. In addition to this, chondroitin sulfate- and dermatan sulfate-containing proteoglycans have also been identified in the primate optic nerve head [84]. Chondroitin and dermatan sulfate are localized to the lamina cribrosa and peripapillary sclera tissues that are load-bearing structures of the optic nerve head and more likely to be exposed to IOP [86].

Multiple integrin subunits have been found in the normal optic nerve head (Table 2). In normal eyes, $\alpha 2, \alpha 3, \alpha 6, \beta 1$, and $\beta 4$ integrin subunits are localized in astrocytes along the margins of laminar beams and within glial columns $[16,86]$, which suggests that integrins $\alpha 2 \beta 1, \alpha 3 \beta 1, \alpha 6 \beta 1$, and $\alpha 6 \beta 4$ may participate in attachment of astrocytes to basement membranes via laminin and sense changes in stress and strain within and anterior to the lamina cribrosa. $\alpha 3, \alpha 5, \alpha 6, \alpha v, \beta 1$, and $\beta 4$ integrin subunits are localized in vascular endothelial cells $[86,98]$, which suggests that vascular endothelial cell response to stress may be mediated by integrins $\alpha 3 \beta 1, \alpha 6 \beta 1$, and $\alpha 6 \beta 4$, along with $\alpha 5 \beta 1$ and $\alpha \mathrm{v} \beta 1$. $\alpha 1, \beta 2$, and $\beta 3$ integrin subunits are rarely expressed in any of the structures of the optic nerve head with a possible exception of $\beta 3$ in larger blood vessel walls [86]. In glaucomatous optic nerve head, cells anterior to the compressed lamina cribrosa show persistent expression for $\alpha 2, \alpha 3, \beta 1$, and $\beta 4$ integrin subunits, whereas the expression for $\alpha 4$ subunit increases and the expression for $\alpha 6$ subunit decreases [86]. In eyes with advanced glaucoma damage, reduced $\alpha 6$ expression and variable expression for $\beta 4$ anterior to the lamina cribrosa suggest astrocyte migration, and increased $\alpha 4$ subunit expression suggests microglia activation [86]. The heavy expression of integrins in association with astrocytes migration and microglia activation of the optic nerve head clearly suggests that these integrins can play an important role in glaucomatous neuropathy.

\section{Concluding Remarks}

In vitro and in vivo data strongly indicate that integrinmediated signaling events can modulate the organization of actin cytoskeleton in TM cells and are associated with astrocytes migration and microglia activation in the optic nerve head of glaucoma patients. As a result, increase in resistance in the TM outflow pathways and ECM remodeling of the optic nerve head occur. While increase in outflow resistance causes an increase in IOP, and the remodeling of the optic nerve head accompanies the optic nerve axons damage. Increase in IOP further adds mechanical stress and strain to optic nerve axons and accelerates axon damages. Integrins appear to be ideal candidates for translating physical stress and strain into cellular responses known to occur in glaucomatous optic neuropathy.

\section{Conflict of Interests}

The authors have no conflict of interests to declare. 


\section{Authors' Contribution}

J. Wang and Y. Zhong contributed equally to this work.

\section{Acknowledgments}

This study was funded by the National Natural Science Foundation of China (nos. 81070728 and 81000373), Shanghai Leading Academic Discipline Project (no. S30205), and Shanghai "Science and Technology Innovation Action Plan" Basic Research Key Project (nos. 11JC1407700 and 11JC1407701).

\section{References}

[1] H. A. Quigley and A. T. Broman, "The number of people with glaucoma worldwide in 2010 and 2020," British Journal of Ophthalmology, vol. 90, no. 3, pp. 262-267, 2006.

[2] P. J. Foster, R. Buhrmann, H. A. Quigley, and G. J. Johnson, "The definition and classification of glaucoma in prevalence surveys," British Journal of Ophthalmology, vol. 86, no. 2, pp. 238-242, 2002.

[3] Y. H. Kwon, J. H. Fingert, M. H. Kuehn, and W. L. Alward, "Primary open angle glaucoma," The New England Journal of Medicine, vol. 360, no. 11, pp. 1113-1124, 2009.

[4] H. A. Quigley, “Glaucoma," The Lancet, vol. 377, no. 9774, pp. 1367-1377, 2011.

[5] A. Sommer, "Intraocular pressure and glaucoma," American Journal of Ophthalmology, vol. 107, no. 2, pp. 186-188, 1989.

[6] J. M. Tielsch, A. Sommer, J. Katz, R. M. Royall, H. A. Quigley, and J. Javitt, "Racial variations in the prevalence of primary open-angle glaucoma: the Baltimore eye survey," Journal of the American Medical Association, vol. 266, no. 3, pp. 369-374, 1991.

[7] B. E. Klein, R. Klein, W. E. Sponsel et al., "Prevalence of glaucoma. The Beaver Dam Eye Study," Ophthalmology, vol. 99, no. 10, pp. 1499-1504, 1992.

[8] P. Mitchell, W. Smith, K. Attebo, and P. R. Healey, "Prevalence of open-angle glaucoma in Australia: the blue mountains eye study," Ophthalmology, vol. 103, no. 10, pp. 1661-1669, 1996.

[9] Collaborative Normal-Tension Glaucoma Study Group, "Comparison of glaucomatous progression between untreated patients with normal-tension glaucoma and patients with therapeutically reduced intraocular pressures," American Journal of Ophthalmology, vol. 126, no. 4, pp. 487-497, 1998.

[10] Collaborative Normal-Tension Glaucoma Study Group, “The effectiveness of intraocular pressure reduction in the treatment of normal-tension glaucoma," American Journal of Ophthalmology, vol. 126, no. 4, pp. 498-505, 1998.

[11] The AGIS Investigators, "The advanced glaucoma intervention study (AGIS). 7. The relationship between control of intraocular pressure and visual field deterioration," American Journal of Ophthalmology, vol. 130, no. 4, pp. 429-440, 2000.

[12] P. R. Lichter, D. C. Musch, B. W. Gillespie et al., "Interim clinical outcomes in the collaborative initial glaucoma treatment study comparing initial treatment randomized to medications or surgery," Ophthalmology, vol. 108, no. 11, pp. 1943-1953, 2001.

[13] M. O. Gordon, J. A. Beiser, J. D. Brandt et al., "The Ocular Hypertension Treatment Study: baseline factors that predict the onset of primary open-angle glaucoma," Archives of Ophthalmology, vol. 120, no. 6, pp. 714-720, 2002.
[14] M. A. Kass, D. K. Heuer, E. J. Higginbotham et al., "The Ocular Hypertension Treatment Study: a randomized trial determines that topical ocular hypotensive medication delays or prevents the onset of primary open-angle glaucoma," Archives of Ophthalmology, vol. 120, no. 6, pp. 701-713, 2002.

[15] M. C. Leske, A. Heijl, M. Hussein, B. Bengtsson, L. Hyman, and E. Komaroff, "Factors for glaucoma progression and the effect of treatment: the early manifest glaucoma trial," Archives of Ophthalmology, vol. 121, no. 1, pp. 48-56, 2003.

[16] M. R. Hernandez, "The optic nerve head in glaucoma: role of astrocytes in tissue remodeling," Progress in Retinal and Eye Research, vol. 19, no. 3, pp. 297-321, 2000.

[17] C. F. Burgoyne, "A biomechanical paradigm for axonal insult within the optic nerve head in aging and glaucoma," Experimental Eye Research, vol. 93, no. 2, pp. 120-132, 2011.

[18] M. Johnson, "What controls aqueous humour outflow resistance?" Experimental Eye Research, vol. 82, no. 4, pp. 545-557, 2006.

[19] D. R. Overby, W. D. Stamer, and M. Johnson, "The changing paradigm of outflow resistance generation: towards synergistic models of the JCT and inner wall endothelium," Experimental Eye Research, vol. 88, no. 4, pp. 656-670, 2009.

[20] A. Alm and S. F. Nilsson, "Uveoscleral outflow-a review," Experimental Eye Research, vol. 88, no. 4, pp. 760-768, 2009.

[21] V. L. Jocson and M. L. Sears, "Experimental aqueous perfusion in enucleated human eyes. Results after obstruction of Schlemm's canal," Archives of Ophthalmology, vol. 86, no. 1, pp. 65-71, 1971.

[22] R. Fuchshofer and E. R. Tamm, "The role of TGF- $\beta$ in the pathogenesis of primary open-angle glaucoma," Cell and Tissue Research, vol. 347, no. 1, pp. 279-290, 2012.

[23] E. Lutjen-Drecoll, T. Shimizu, M. Rohrbach, and J. W. Rohen, "Quantitative analysis of "plaque material" in the inner- and outer wall of Schlemm's canal in normal- and glaucomatous eyes," Experimental Eye Research, vol. 42, no. 5, pp. 443-455, 1986.

[24] O. Y. Tektas and E. Lütjen-Drecoll, "Structural changes of the trabecular meshwork in different kinds of glaucoma," Experimental Eye Research, vol. 88, no. 4, pp. 769-775, 2009.

[25] E. Lütjen-Drecoll, "Morphological changes in glaucomatous eyes and the role of TGF beta2 for the pathogenesis of the disease," Experimental Eye Research, vol. 81, no. 1, pp. 1-4, 2005.

[26] E. R. Tamm and R. Fuchshofer, "What increases outflow resistance in primary open-angle glaucoma?" Survey of Ophthalmology, vol. 52, no. 6, supplement, pp. S101-S104, 2007.

[27] J. M. Bradley, J. Vranka, C. M. Colvis et al., "Effect of matrix metalloproteinases activity on outflow in perfused human organ culture," Investigative Ophthalmology and Visual Science, vol. 39, no. 13, pp. 2649-2658, 1998.

[28] A. Lepple-Wienhues, F. Stahl, and M. Wiederholt, "Differential smooth muscle-like contractile properties of trabecular meshwork and ciliary muscle," Experimental Eye Research, vol. 53, no. 1, pp. 33-38, 1991.

[29] M. Wiederholt, H. Thieme, and F. Stumpff, "The regulation of trabecular meshwork and ciliary muscle contractility," Progress in Retinal and Eye Research, vol. 19, no. 3, pp. 271-295, 2000.

[30] B. Tian, B. Geiger, D. L. Epstein, and P. L. Kaufman, "Cytoskeletal involvement in the regulation of aqueous humor outflow," Investigative Ophthalmology and Visual Science, vol. 41, no. 3, pp. 619-623, 2000. 
[31] B. Tian, B. T. Gabelt, B. Geiger, and P. L. Kaufman, "The role of the actomyosin system in regulating trabecular fluid outflow," Experimental Eye Research, vol. 88, no. 4, pp. 713-717, 2009.

[32] J. A. Last, T. Pan, Y. Ding et al., "Elastic modulus determination of normal and glaucomatous human trabecular meshwork," Investigative Ophthalmology and Visual Science, vol. 52, no. 5, pp. 2147-2152, 2011.

[33] A. van der Flier and A. Sonnenberg, "Function and interactions of integrins," Cell and Tissue Research, vol. 305, no. 3, pp. 285298, 2001.

[34] R. O. Hynes, "Integrins: bidirectional, allosteric signaling machines," Cell, vol. 110, no. 6, pp. 673-687, 2002.

[35] C. A. Lowell and T. N. Mayadas, "Overview: studying integrins in vivo," Methods in Molecular Biology, vol. 757, pp. 369-397, 2012.

[36] E. F. Plow, T. A. Haas, L. Zhang, J. Loftus, and J. W. Smith, "Ligand binding to integrins," Journal of Biological Chemistry, vol. 275, no. 29, pp. 21785-21788, 2000.

[37] M. Barczyk, S. Carracedo, and D. Gullberg, "Integrins," Cell and Tissue Research, vol. 339, no. 1, pp. 269-280, 2010.

[38] L. Zhou, S. R. Zhang, and B. Y. J. T. Yue, "Adhesion of human trabecular meshwork cells to extracellular matrix proteins: roles and distribution of integrin receptors," Investigative Ophthalmology and Visual Science, vol. 37, no. 1, pp. 104-113, 1996.

[39] L. Zhou, I. Maruyama, Y. Li, E. L. Cheng, and B. Y. J. T. Yue, "Expression of integrin receptors in the human trabecular meshwork," Current Eye Research, vol. 19, no. 5, pp. 395-402, 1999.

[40] M. S. Filla, X. Liu, T. D. Nguyen et al., "In vitro localization of TIGR/MYOC in trabecular meshwork extracellular matrix and binding to fibronectin," Investigative Ophthalmology and Visual Science, vol. 43, no. 1, pp. 151-161, 2002.

[41] J. Ueda and B. Y. J. T. Yue, "Distribution of myocilin and extracellular matrix components in the corneoscleral meshwork of human eyes," Investigative Ophthalmology and Visual Science, vol. 44, no. 11, pp. 4772-4779, 2003.

[42] M. S. Filla, A. Woods, P. L. Kaufman, and D. M. Peters, " $\beta 1$ and $\beta 3$ integrins cooperate to induce syndecan-4-containing crosslinked actin networks in human trabecular meshwork cells," Investigative Ophthalmology and Visual Science, vol. 47, no. 5, pp. 1956-1967, 2006.

[43] S. Diskin, Z. Cao, H. Leffler, and N. Panjwani, “The role of integrin glycosylation in galectin-8-mediated trabecular meshwork cell adhesion and spreading," Glycobiology, vol. 19, no. 1, pp. 2937, 2009.

[44] K. M. Perkumas and W. D. Stamer, "Protein markers and differentiation in culture for Schlemm's canal endothelial cells," Experimental Eye Research, vol. 96, no. 1, pp. 82-87, 2012.

[45] H. Tian, E. Sanders, A. Reynolds, F. van Roy, and J. van Hengel, "Ocular anterior segment dysgenesis upon ablation of p120 catenin in neural crest cells," Investigative Ophthalmology and Visual Science, vol. 53, no. 9, pp. 5139-5153, 2012.

[46] W. D. Stamer, A. T. Read, G. M. Sumida, and C. R. Ethier, "Sphingosine-1-phosphate effects on the inner wall of Schlemm's canal and outflow facility in perfused human eyes," Experimental Eye Research, vol. 89, no. 6, pp. 980-988, 2009.

[47] J. M. Gonzalez Jr., J. A. Faralli, J. M. Peters, J. R. Newman, and D. M. Peters, "Effect of heparin II domain of fibronectin on actin cytoskeleton and adherens junctions in human trabecular meshwork cells," Investigative Ophthalmology and Visual Science, vol. 47, no. 7, pp. 2924-2931, 2006.
[48] K. E. Keller, J. M. Bradley, M. J. Kelley, and T. S. Acott, "Effects of modifiers of glycosaminoglycan biosynthesis on outflow facility in perfusion culture," Investigative Ophthalmology and Visual Science, vol. 49, no. 6, pp. 2495-2505, 2008.

[49] K. E. Keller, M. J. Kelley, and T. S. Acott, "Extracellular matrix gene alternative splicing by trabecular meshwork cells in response to mechanical stretching," Investigative Ophthalmology and Visual Science, vol. 48, no. 3, pp. 1164-1172, 2007.

[50] C. R. Hann, M. J. Springett, X. Wang, and D. H. Johnson, "Ultrastructural localization of collagen IV, fibronectin, and laminin in the trabecular meshwork of normal and glaucomatous eyes," Ophthalmic Research, vol. 33, no. 6, pp. 314-324, 2001.

[51] J. A. Faralli, M. K. Schwinn, J. M. Gonzalez, M. S. Filla, and D. M. Peters, "Functional properties of fibronectin in the trabecular meshwork," Experimental Eye Research, vol. 88, no. 4, pp. 689693, 2009.

[52] T. Fujimoto, T. Inoue, T. Kameda et al., "Involvement of RhoA/Rho-associated kinase signal transduction pathway in dexamethasone-induced alterations in aqueous outflow," Investigative Ophthalmology and Visual Science, vol. 53, no. 11, pp. 7097-7108, 2012.

[53] H. T. Steely, S. L. Browder, M. B. Julian, S. T. Miggans, K. L. Wilson, and A. F. Clark, "The effects of dexamethasone on fibronectin expression in cultured human trabecular meshwork cells," Investigative Ophthalmology and Visual Science, vol. 33, no. 7, pp. 2242-2250, 1992.

[54] L. Zhou, Y. Li, and B. Y. Yue, "Glucocorticoid effects on extracellular matrix proteins and integrins in bovine trabecular meshwork cells in relation to glaucoma," International Journal of Molecular Medicine, vol. 1, no. 2, pp. 339-346, 1998.

[55] N. Tane, S. Dhar, S. Roy, A. Pinheiro, A. Ohira, and S. Roy, "Effect of excess synthesis of extracellular matrix components by trabecular meshwork cells: possible consequence on aqueous outflow," Experimental Eye Research, vol. 84, no. 5, pp. 832-842, 2007.

[56] J. E. Dickerson Jr., T. T. Steely, S. L. English-Wright, and A. F. Clark, "The effect of dexamethasone on integrin and laminin expression in cultured human trabecular meshwork cells," Experimental Eye Research, vol. 66, no. 6, pp. 731-738, 1998.

[57] B. Junglas, A. H. L. Yu, U. Welge-Lüssen, E. R. Tamm, and R. Fuchshofer, "Connective tissue growth factor induces extracellular matrix deposition in human trabecular meshwork cells," Experimental Eye Research, vol. 88, no. 6, pp. 1065-1075, 2009.

[58] M. S. Filla, M. K. Schwinn, A. K. Nosie, R. W. Clark, and D. M. Peters, "Dexamethasone-associated cross-linked actin network formation in human trabecular meshwork cells involves $\beta 03$ integrin signaling," Investigative Ophthalmology and Visual Science, vol. 52, no. 6, pp. 2952-2959, 2011.

[59] E. Lazarides, "Actin, $\alpha$ actinin, and tropomyosin interaction in the structural organization of actin filaments in nonmuscle cells," Journal of Cell Biology, vol. 68, no. 2, pp. 202-219, 1976.

[60] W. E. Gordon III and A. Bushnell, "Immunofluorescent and ultrastructural studies of polygonal microfilament networks in respreading non-muscle cells," Experimental Cell Research, vol. 120, no. 2, pp. 335-348, 1979.

[61] J. M. Sanger, B. Mittal, M. Pochapin, and J. W. Sanger, "Observations of microfilament bundles in living cells microinjected with fluorescently labelled contractile proteins," Journal of Cell Science. Supplement, vol. 5, pp. 17-44, 1986.

[62] K. Wilson, M. D. McCartney, S. T. Miggans, and A. F. Clark, "Dexamethasone induced ultrastructural changes in cultured 
human trabecular meshwork cells," Current Eye Research, vol. 12, no. 9, pp. 783-793, 1993.

[63] A. F. Clark, K. Wilson, M. D. McCartney, S. T. Miggans, M. Kunkle, and W. Howe, "Glucocorticoid-induced formation of crosslinked actin networks in cultured human trabecular meshwork cells," Investigative Ophthalmology and Visual Science, vol. 35, no. 1, pp. 281-294, 1994.

[64] A. F. Clark, D. Lane, K. Wilson, S. T. Miggans, and M. D. McCartney, "Inhibition of dexamethasone-induced cytoskeletal changes in cultured human trabecular meshwork cells by tetrahydrocortisol," Investigative Ophthalmology and Visual Science, vol. 37, no. 5, pp. 805-813, 1996.

[65] A. F. Clark, S. T. Miggans, K. Wilson, S. Browder, and M. D. McCartney, "Cytoskeletal changes in cultured human glaucoma trabecular meshwork cells," Journal of Glaucoma, vol. 4, no. 3, pp. 183-188, 1995.

[66] M. J. Hoare, I. Grierson, D. Brotchie, N. Pollock, K. Cracknell, and A. F. Clark, "Cross-linked actin networks (CLANs) in the trabecular meshwork of the normal and glaucomatous human eye in situ," Investigative Ophthalmology and Visual Science, vol. 50, no. 3, pp. 1255-1263, 2009.

[67] A. T. Read, D. W. Chan, and C. R. Ethier, "Actin structure in the outflow tract of normal and glaucomatous eyes," Experimental Eye Research, vol. 82, no. 6, pp. 974-985, 2006.

[68] R. J. Wordinger and A. F. Clark, "Effects of glucocorticoids on the trabecular meshwork: towards a better understanding of glaucoma," Progress in Retinal and Eye Research, vol. 18, no. 5, pp. 629-667, 1999.

[69] X. Liu, Z. Wu, N. Sheibani, C. R. Brandt, J. R. Polansky, and P. L. Kaufman, "Low dose latrunculin-A inhibits dexamethasoneinduced changes in the actin cytoskeleton and alters extracellular matrix protein expression in cultured human trabecular meshwork cells," Experimental Eye Research, vol. 77, no. 2, pp. 181-188, 2003.

[70] A. F. Clark, D. Brotchie, A. T. Read et al., "Dexamethasone alters F-actin architecture and promotes cross-linked actin network formation in human trabecular meshwork tissue," Cell Motility and the Cytoskeleton, vol. 60, no. 2, pp. 83-95, 2005.

[71] M. S. Filla, M. K. Schwinn, N. Sheibani, P. L. Kaufman, and D. M. Peters, "Regulation of cross-linked actin network (CLAN) formation in human trabecular meshwork (HTM) cells by convergence of distinct $\beta 1$ and $\beta 3$ integrin pathways," Investigative Ophthalmology and Visual Science, vol. 50, no. 12, pp. 5723-5731, 2009.

[72] J. M. Gonzalez Jr., Y. Hu, B. T. Gabelt, P. L. Kaufman, and D. M. Peters, "Identification of the active site in the heparin II domain of fibronectin that increases outflow facility in cultured monkey anterior segments," Investigative Ophthalmology and Visual Science, vol. 50, no. 1, pp. 235-241, 2009.

[73] M. K. Schwinn, J. M. Gonzalez, B. T. Gabelt, N. Sheibani, P. L. Kaufman, and D. M. Peters, "Heparin II domain of fibronectin mediates contractility through an $\alpha 4 \beta 1$ co-signaling pathway," Experimental Cell Research, vol. 316, no. 9, pp. 1500-1512, 2010.

[74] J. A. Peterson, N. Sheibani, G. David, A. Garcia-Pardo, and D. M. Peters, "Heparin II domain of fibronectin uses $\alpha 4 \beta 1$ integrin to control focal adhesion and stress fiber formation, independent of syndecan-4," Journal of Biological Chemistry, vol. 280, no. 8, pp. 6915-6922, 2005.

[75] S. Diskin, W. S. Chen, Z. Cao et al., "Galectin-8 promotes cytoskeletal rearrangement in trabecular meshwork cells through activation of Rho signaling," PLoS ONE, vol. 7, no. 9, Article ID e44400, 2012.
[76] S. S. VanderWyst, K. M. Perkumas, A. Thomas Read, D. R. Overby, and W. Daniel Stamer, "Structural basement membrane components and corresponding integrins in Schlemm's canal endothelia," Molecular Vision, vol. 17, pp. 199-209, 2011.

[77] K. Tervo, T. Päällysaho, I. Virtanen, and T. Tervo, "Integrins in human anterior chamber angle," Graefe's Archive for Clinical and Experimental Ophthalmology, vol. 233, no. 5, pp. 291-295, 1995.

[78] M. R. Hernandez, F. Igoe, and A. H. Neufeld, "Extracellular matrix of the human optic nerve head," American Journal of Ophthalmology, vol. 102, no. 2, pp. 139-148, 1986.

[79] M. R. Hernandez, X. X. Luo, F. Igoe, and A. H. Neufeld, "Extracellular matrix of the human lamina cribrosa," American Journal of Ophthalmology, vol. 104, no. 6, pp. 567-576, 1987.

[80] J. C. Morrison, J. A. Jerdan, N. L. L'Hernault, and H. A. Quigley, "The extracellular matrix composition of the monkey optic nerve head," Investigative Ophthalmology and Visual Science, vol. 29, no. 7, pp. 1141-1150, 1988.

[81] M. R. Hernandez, X. X. Luo, W. Andrzejewske, and A. H. Neufeld, "Age-related changes in the extracellular matrix of the human optic nerve head," American Journal of Ophthalmology, vol. 107, no. 5, pp. 476-484, 1989.

[82] J. C. Morrison, J. A. Jerdan, M. E. Dorman, and H. A. Quigley, "Structural proteins of the neonatal and adult lamina cribrosa," Archives of Ophthalmology, vol. 107, no. 8, pp. 1220-1224, 1989.

[83] J. C. Morrison, N. L. L. 'Hernault, J. A. J. erdan, and H. A. Quigley, "Ultrastructural location of extracellular matrix components in the optic nerve head," Archives of Ophthalmology, vol. 107, no. 1, pp. 123-129, 1989.

[84] J. C. Morrison, P. Rask, E. C. Johnson, and L. Deppmeier, "Chondroitin sulfate proteoglycan distribution in the primate optic nerve head," Investigative Ophthalmology and Visual Science, vol. 35, no. 3, pp. 838-845, 1994.

[85] J. Morrison, S. Farrell, E. Johnson, L. Deppmeier, C. G. Moore, and E. Grossmann, "Structure and composition of the rodent lamina cribrosa," Experimental Eye Research, vol. 60, no. 2, pp. 127-135, 1995.

[86] J. C. Morrison, "Integrins in the optic nerve head: potential roles in glaucomatous optic neuropathy (an American ophthalmological society thesis)," Transactions of the American Ophthalmological Society, vol. 104, pp. 453-477, 2006.

[87] T. Fukuchi, J. Ueda, H. Abe, and S. Sawaguchi, "Cell adhesion glycoproteins in the human lamina cribrosa," Japanese Journal of Ophthalmology, vol. 45, no. 4, pp. 363-367, 2001.

[88] Y. Morcos and T. Chan-Ling, "Concentration of astrocytic filaments at the retinal optic nerve junction is coincident with the absence of intra-retinal myelination: comparative and developmental evidence," Brain Cell Biology, vol. 29, no. 9, pp. 665-678, 2000.

[89] J. D. Pena, H. J. Varela, C. S. Ricard, and M. R. Hernandez, "Enhanced tenascin expression associated with reactive astrocytes in human optic nerve heads with primary open angle glaucoma," Experimental Eye Research, vol. 68, no. 1, pp. 29-40, 1999.

[90] M. N. Rudzinski, L. Chen, and M. R. Hernandez, "Antiangiogenic characteristics of astrocytes from optic nerve heads with primary open-angle glaucoma," Archives of Ophthalmology, vol. 126, no. 5, pp. 679-685, 2008.

[91] F. J. Carreras, D. Porcel, M. Alaminos, and I. Garzón, “Cell-cell adhesion in the prelaminar region of the optic nerve head: a possible target for ionic stress," Ophthalmic Research, vol. 42, no. 2, pp. 106-111, 2009. 
[92] H. Gerhardt, G. Rascher, J. Schuck, U. Weigold, C. Redies, and H. Wolburg, "R- and B-cadherin expression defines subpopulations of glial cells involved in axonal guidance in the optic nerve head of the chicken," GLIA, vol. 31, no. 2, pp. 131-143, 2000.

[93] L. A. Lagunowich, J. C. Schneider, S. Chasen, and G. B. Grunwald, "Immunohistochemical and biochemical analysis of N-cadherin expression during CNS development," Journal of Neuroscience Research, vol. 32, no. 2, pp. 202-208, 1992.

[94] R. P. Kirwan, R. J. Wordinger, A. F. Clark, and C. J. O’Brien, "Differential global and extra-cellular matrix focused gene expression patterns between normal and glaucomatous human lamina cribrosa cells," Molecular Vision, vol. 15, pp. 76-88, 2009.

[95] R. P. Kirwan, C. H. Fenerty, J. Crean, R. J. Wordinger, A. F. Clark, and C. J. O'Brien, "Influence of cyclical mechanical strain on extracellular matrix gene expression in human lamina cribrosa cells in vitro," Molecular Vision, vol. 11, pp. 798-810, 2005.

[96] R. P. Kirwan, M. O. Leonard, M. Murphy, A. F. Clark, and C. J. O’Brien, “Transforming Growth factor- $\beta$-regulated gene transcription and protein expression in human GFAP-negative lamina cribrosa cells," GLIA, vol. 52, no. 4, pp. 309-324, 2005.

[97] R. Fuchshofer, M. Birke, U. Welge-Lussen, D. Kook, and E. Lütjen-Drecoll, "Transforming growth factor- $\beta 2$ modulated extracellular matrix component expression in cultured human optic nerve head astrocytes," Investigative Ophthalmology and Visual Science, vol. 46, no. 2, pp. 568-578, 2005.

[98] R. B. Brem, S. G. Robbins, D. J. Wilson et al., "Immunolocalization of integrins in the human retina," Investigative Ophthalmology and Visual Science, vol. 35, no. 9, pp. 3466-3474, 1994. 


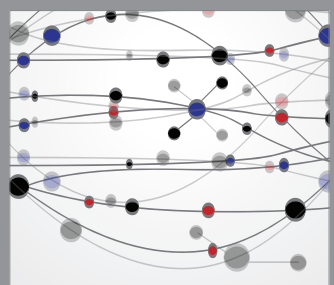

The Scientific World Journal
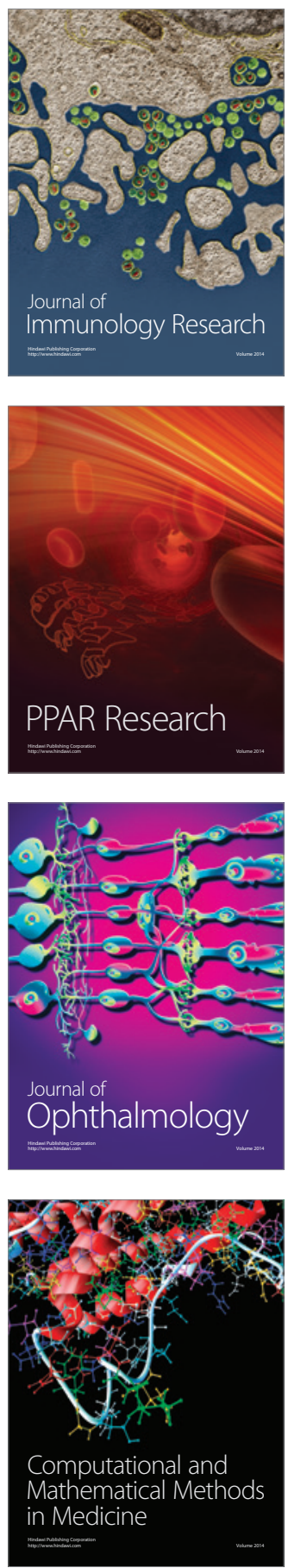

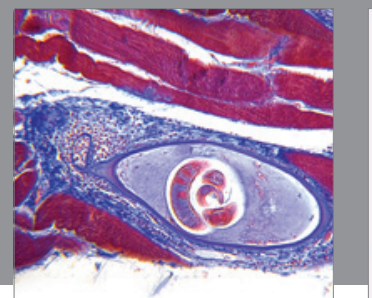

Gastroenterology

Research and Practice
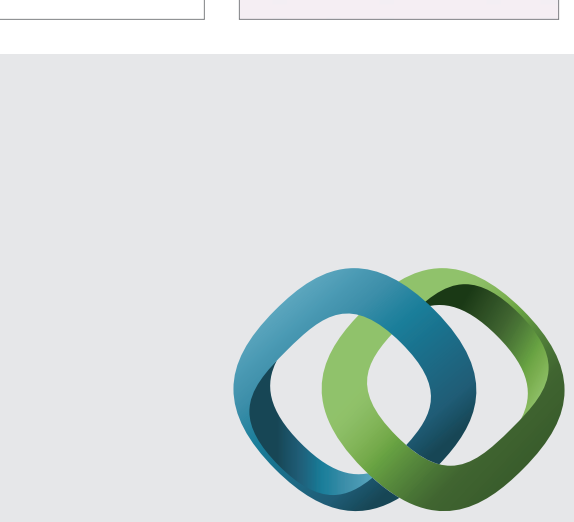

\section{Hindawi}

Submit your manuscripts at

http://www.hindawi.com
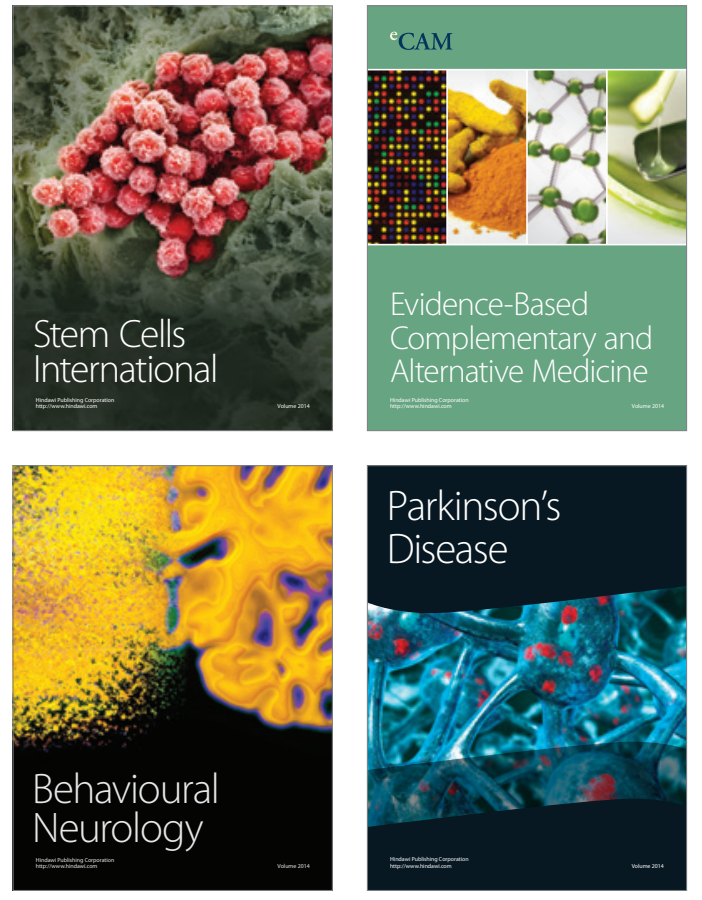
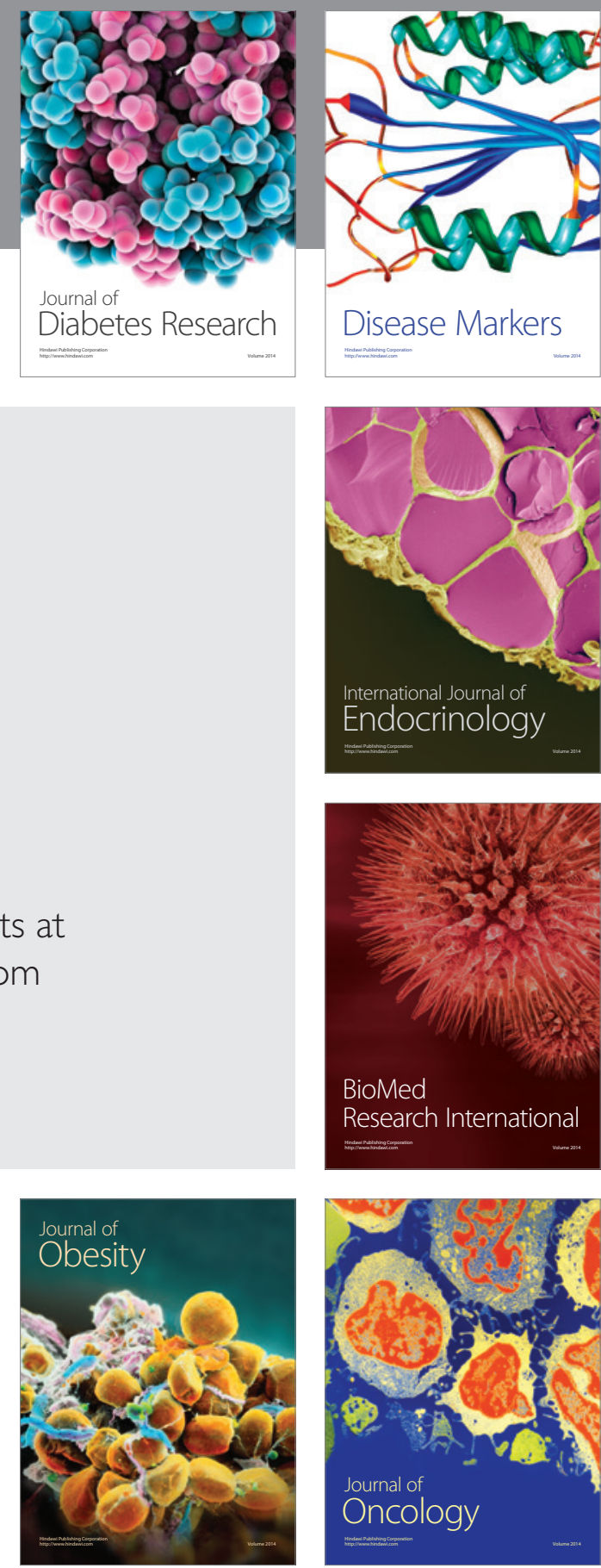

Disease Markers
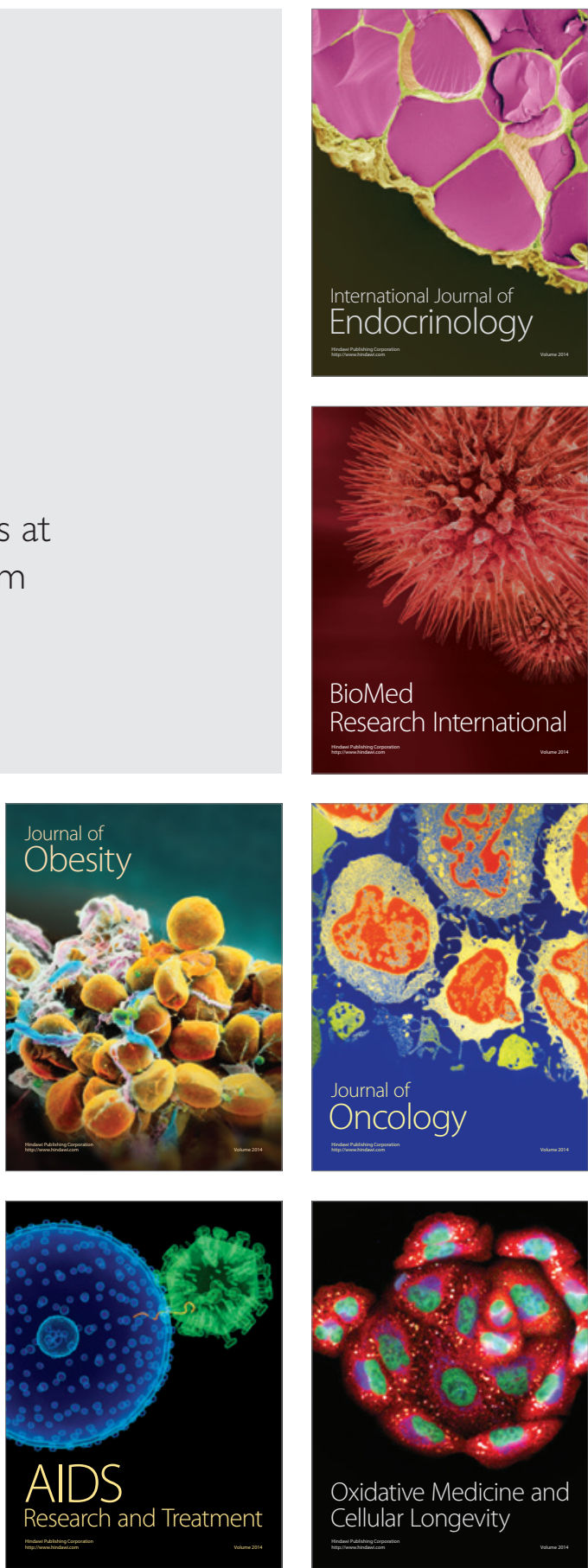